\section{Vitamin D and bacterial pneumonias: the question of causality}

\author{
Richard James Allen
}

Vitamin D controls calcium and phosphates in the body, maintains healthy bones and muscles, and has been shown to play an important role in the regulation of the innate immune system. Vitamin D is found in some foods, but the main source for most people comes from sunlight. Over recent years, there has been much debate as to the benefit of vitamin D supplementation and the UK's National Health Service now advises everyone to consider vitamin D supplementation during winter months. ${ }^{1}$

A recent systematic review ${ }^{2}$ of 25 randomised controlled trials (collectively containing over 11000 individuals) found that vitamin D supplementation showed an association with reduced acute-respiratory tract infections, particularly in those with baseline circulating 25-hydroxyvitamin D levels less than $25 \mathrm{nmol} / \mathrm{L}$. These results are supported by observational studies that suggest low vitamin D levels are associated with an increased risk of respiratory tract infections. ${ }^{3} 4$ Pneumonia (a common lower respiratory tract infection) may be caused by bacterial, viral or fungal infections, and the discussion around the benefit of vitamin $\mathrm{D}$ supplementation to reduce the risk of viral pneumonias has intensified this year due to the coronavirus pandemic. $^{56}$

However, observational studies only allow us to study associations and do not test for causation, as there may be confounding factors. For example, smoking may lead to lower vitamin D levels and also to a higher risk of pneumonias, which could lead to a spurious association between vitamin D levels and pneumonia risk. Randomised controlled trials give us a better indication for whether an intervention (eg, vitamin D supplementation) is casual. However, we cannot determine whether naturally low vitamin D levels increase risk of pneumonias through randomised controlled trials as these vitamin D levels are not determined by study investigators. Therefore, alternative approaches to test for causation are required.

Mendelian randomisation (MR) aims to investigate whether an exposure (eg, low

Correspondence to Dr Richard James Allen, Department of Health Sciences, University of Leicester, Leicester, UK; rja34@leicester.ac.uk vitamin D levels) causes an outcome (eg, bacterial pneumonias) by using genetic variants as instrumental variables. MR can be thought of as a naturally occurring randomised trial. ${ }^{7}$ At birth, individuals are randomly assigned genetic variants that affect an individual's exposure levels. We can then test for differences in the outcome between individuals randomly assigned to each of the genetic variants. Using genetics has two key advantages over traditional epidemiological approaches; first, genetic variants are fixed, meaning there is no reverse causation; and second, very few factors affect an individual's genome, meaning the risk of confounding is also reduced. The choice of genetic variants to use as instrumental variables is important and they must meet three assumptions (figure 1): (1) the variants are associated with the exposure, (2) the variants are not associated with known or unknown confounders, and (3) the variants are only associated with the outcome through the exposure. It can be difficult to test these assumptions, and if they are broken, then an MR analysis may provide biased results.

Lower respiratory infections are the fourth main cause of death globally, ${ }^{8}$ so understanding which risk factors cause pneumonias, particularly factors that are easily modifiable, is a key question in medical research. In this issue of Thorax, Çolak and colleagues ${ }^{9}$ present an MR study to determine whether low vitamin D levels lead to increased risk of bacterial pneumonias. The main strength of the

paper by Çolak and colleagues is the study population used. They were able to study up to 116000 individuals with considerable follow-up time (up to 38 years) by using two Danish population cohorts. By defining cases as individuals with at least one recorded acute emergency department or hospital visit due to a bacterial pneumonia (defined using the ICD-8 codes $481 \mathrm{xx}-486 \mathrm{xx}$ and ICD-10 codes A481, J13-J16, J170 and J18), they were able to identify just under 14000 bacterial pneumonias. One possible limitation of this study population is that only an ethnically homogeneous white Danish population was included, meaning care should be taken when interpreting the results of this study outside of this population. Furthermore, only bacterial pneumonias were investigated, so the results of this study may not be generalisable to other forms of pneumonia or respiratory tract infections. Seven genetic variants around the CYP2R1, DHCR7, GEMIN2 and HAL genes, previously shown to be associated with vitamin D levels, were selected to be used as instrumental variables for the MR analysis.

Both observational and MR analyses showed those individuals with lower 25-hydroxyvitamin D levels were at a higher risk of bacterial pneumonias, which appears to be especially true when looking at older individuals in the observational data.

The authors note that they cannot rule out the assumptions of the MR analysis being broken (particularly for the genetic variants near CYP2R1 and assumption three in figure 1), meaning the results should be interpreted with caution. None of the genetic instruments showed an association with known confounders (age, sex, body mass index, smoking,

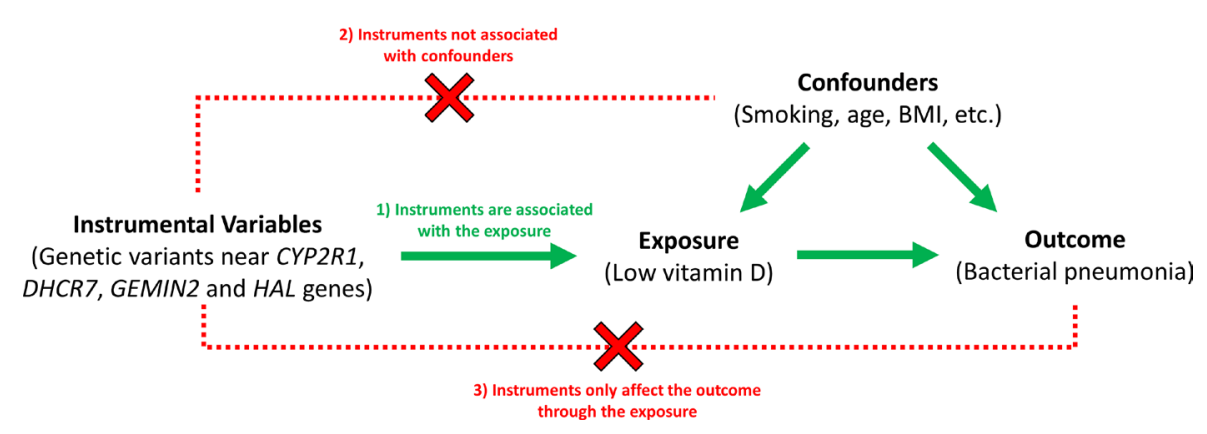

Figure 1 Mendelian randomisation analysis of vitamin D and bacterial pneumonias. This figure shows the three main assumptions of a Mendelian randomisation analysis: assumption 1, the genetic instrumental variables are associated with the exposure; assumption 2, the genetic instrumental variables are not associated with any known or unknown confounders; assumption 3 , the genetic instrumental variables are only associated with the outcome by acting through the exposure of interest. BMI, body mass index. 
alcohol consumption, estimated glomerular filtration rate and chronic diseases). Although this means there is no evidence that assumption 2 (ie, that the variants are not associated with confounders) has been broken, it is not possible to be completely sure that the variants do not act through unknown confounders. Sensitivity analyses using MR Egger and weighted median estimators (both of which allow for some of the MR assumptions to be loosened) did show generally similar results suggesting that there are some robustness to the results. The paper crucially also uses control diseases to show that the analysis is not generating spurious associations.

Therefore, although the results do not provide conclusive evidence of causality, this paper does add to the debate and supports previous studies that suggest vitamin $\mathrm{D}$ may play a role in bacterial pneumonia risk.

Twitter Richard James Allen @rjallen513

Contributors RJA wrote the manuscript.

Funding RJA is an Action for Pulmonary Fibrosis Research Fellow.

Competing interests None declared.

Patient consent for publication Not required.

Provenance and peer review Commissioned externally peer reviewed.

\section{(2)}

\section{OPEN ACCESS}

Open access This is an open access article distributed in accordance with the Creative Commons Attribution Non Commercial (CC BY-NC 4.0) license, which permits others to distribute, remix, adapt, build upon this work non-commercially, and license their derivative works on different terms, provided the original work is properly cited, appropriate credit is given, any changes made indicated, and the use is non-commercial. See: http:// creativecommons.org/licenses/by-nc/4.0/.

(c) Author(s) (or their employer(s)) 2021. Re-use permitted under CC BY-NC. No commercial re-use. See rights and permissions. Published by BMJ.

\section{Check for updates}

To cite Allen RJ. Thorax 2021;76:426-427.

Accepted 14 December 2020

Published Online First 2 March 2021

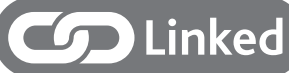

http://dx.doi.org/10.1136/thoraxjnl-2020-215288

Thorax 2021:76:426-427.

doi:10.1136/thoraxjnl-2020-216375

\section{REFERENCES}

1 National Health Service. Vitamins and minerals: vitamin D, 2020. Available: https://www.nhs.uk/conditions/ vitamins-and-minerals/vitamin-d/ [Accessed $150 \mathrm{Oct}$ 2020].

2 Martineau AR, Jolliffe DA, Hooper RL, et al. Vitamin D supplementation to prevent acute respiratory tract infections: systematic review and meta-analysis of individual participant data. BMJ 2017:356:i6583.

3 Ginde AA, Mansbach JM, Camargo CA. Association between serum 25-hydroxyvitamin $D$ level and upper respiratory tract infection in the third National Health and Nutrition Examination Survey. Arch Intern Med 2009;169:384-90.

4 Jovanovich AJ, Ginde AA, Holmen J, et al. Vitamin D level and risk of community-acquired pneumonia and sepsis. Nutrients 2014;6:2196-205.

5 llie PC, Stefanescu S, Smith L. The role of vitamin D in the prevention of coronavirus disease 2019 infection and mortality. Aging Clin Exp Res 2020;32:1195-8.

6 Grant WB, Lahore H, McDonnell SL, et al. Evidence that vitamin $D$ supplementation could reduce risk of influenza and COVID-19 infections and deaths. Nutrients 2020;12:988.

7 Thanassoulis G, O'Donnell CJ. Mendelian randomization: nature's randomized trial in the post-genome era. JAMA 2009;301:2386-8.

8 World Health Organization. The top 10 causes of death, 2018. Available: https://www.who.int/news-room/factsheets/detail/the-top-10-causes-of-death [Accessed 15 Oct 2020].

9 Çolak Y, Nordestgaard BG, Afzal S. Low vitamin D and risk of bacterial pneumonias: Mendelian randomisation studies in two population-based cohorts. Thorax 2021;76:468-78. 